\title{
High reactivity of silicon suboxide clusters
}

\author{
R. Q. Zhang, ${ }^{*}$ T. S. Chu, H. F. Cheung, N. Wang, and S. T. Lee \\ Center of Super-Diamond and Advanced Films (COSDAF) \& Department of Physics and Materials Science, \\ City University of Hong Kong, 83 Tat Chee Avenue, Kowloon, Hong Kong, China
}

(Received 27 February 2001; revised manuscript received 30 April 2001; published 28 August 2001)

\begin{abstract}
The recent silicon-oxide-assisted formation of $\mathrm{Si}$ nanostructures has been studied based on quantummechanical calculations of $\mathrm{Si}_{n} \mathrm{O}_{m}(n, m=1-8)$ clusters. We found that (1) energetically the most favorable small silicon-oxide clusters have $\mathrm{O}$ atomic ratios at around 0.6 , and (2) remarkably high reactivity at the $\mathrm{Si}$ atoms exists in silicon suboxide $\mathrm{Si}_{n} \mathrm{O}_{m}$ clusters with $2 n>m$. The results show that the formation of $\mathrm{Si}-\mathrm{Si}$ bonds is preferred and thus facilitates the nucleation of $\mathrm{Si}$ nanostructures when silicon suboxide clusters come together or stack to a substrate.
\end{abstract}

DOI: 10.1103/PhysRevB.64.113304

PACS number(s): 61.46. $+\mathrm{w}, 73.22 .-\mathrm{f}$

Silicon oxide has found important applications in wide fields such as microelectronics, optical communications, and thin-film technology. ${ }^{1-3}$ Recent work $^{4}$ further showed that silicon oxide could also play an important role in the fabrication of an important nanometer material, the $\mathrm{Si}$ nanowire, ${ }^{5,6}$ which has attracted much attention for its interesting quantum confinement effect as well as useful electrical, optical, mechanical, and chemical properties. The formation of $\mathrm{Si}$ nanowires was achieved by using $\mathrm{Si}$ powder sources mixed with $\mathrm{SiO}_{2} \cdot{ }^{4}$ A high yield of nanowires has been obtained when the chemical compositions of $\mathrm{Si}$ and $\mathrm{O}$ in the source are approximately equal. ${ }^{7}$ On the contrary, the important role of oxide is not needed in the conventional growth mechanisms of nanowires. ${ }^{8,9}$ To understand the oxide-assisted formation mechanism, the exploration of silicon oxide clusters about their geometric, electronic, and chemical properties would provide useful information.

To promote various technological applications based on silicon oxide, theoretical investigations have been performed on small silicon oxide clusters. Systems, such as isolated $\mathrm{SiO}_{2}$, gas-phase oligomers $\left(\mathrm{SiO}_{2}\right)_{n} \quad(n \leqslant 8, \quad n=18),{ }^{10}$ $\mathrm{Si}\left(\mathrm{SiO}_{2}\right)_{n} \quad(n=2,3), \quad\left(\mathrm{SiO}_{2}\right)_{n} \quad(n=1-4), \quad\left(\mathrm{SiO}_{2}\right)_{n} \quad(n$ $=3-5),{ }^{11} \mathrm{Si}_{3} \mathrm{O}_{m}(m=1-6),{ }^{12} \mathrm{Si}_{2} \mathrm{O}_{4}{ }^{2-}, \mathrm{Si}_{2} \mathrm{O}_{5}{ }^{2-},{ }^{13}$ charged and neutral $\mathrm{Si}_{n} \mathrm{O}_{m}(n \leqslant 6, m \leqslant 12),{ }^{14}$ and $(\mathrm{SiO})_{n}(n \leqslant 5),{ }^{15}$ have been studied using $a b$ initio theories. Information achieved includes geometric structures, energetics, bonding, energy gaps, and valence electronic structures of these species. However, understanding of the oxide-assisted formation of $\mathrm{Si}$ nanowires in which silicon oxide acts as a special "catalyst" would require a systematic study of $\mathrm{Si}_{n} \mathrm{O}_{m}$. In this work, we have made such a systematic study of $\mathrm{Si}_{n} \mathrm{O}_{m}$ $(n, m=1-8)$ at the quantum-mechanical level, aiming at elucidating the oxide-assisted formation mechanism of silicon nanowires.

Energetically, the more favorable structure has been searched for each composition of $\mathrm{Si}_{n} \mathrm{O}_{m}(n, m=1-8)$ by means of calculations with density functional theory (DFT). The DFT calculations in this work used the popular B3LYP method, which is based on the Becke-type three-parameter density functional theory. ${ }^{16}$ An economic basis set, where 3-21G and 6-31G* were selected to describe $\mathrm{Si}$ and $\mathrm{O}$, respectively, according to their electronegativities and charge transfers, ${ }^{17}$ was used in B3LYP calculations for most of the atomic clusters considered. The standard $6-31 \mathrm{G}^{*}$ was also used in B3LYP calculations for small clusters $(m+n<12)$. Table I lists the geometric parameters and cohesion energies of $\mathrm{SiO}$ and $\mathrm{SiO}_{2}$ species calculated with different levels of theories. Spin polarization energies have been included in the calculations for free $\mathrm{Si}$ and $\mathrm{O}$ atoms when obtaining the cohesion energies. It is shown that B3LYP of DFT calculations predict quite accurate geometric parameters while they un-

TABLE I. Geometric parameters and cohesion energies per atom $(\mathrm{eV})$ of $\mathrm{SiO}$ and $\mathrm{SiO}_{2}$ calculated with different theoretical methods.

\begin{tabular}{ccccc}
\hline \hline & \multicolumn{4}{c}{ Method } \\
& B3LYP/3-21G:Si; 6-31G*:O & B3LYP/6-31G* & G2MP2 & Other calculations (Ref. 14) \\
\cline { 2 - 5 } $\mathrm{SiO}$ & 1.54 & Bond length $(\AA)$ \\
$\mathrm{SiO}_{2}(D 2 h)$ & 1.54 & 1.52 & 1.54 & 1.54 \\
\hline \multirow{2}{*}{$\mathrm{SiO}$} & -3.66 & Cohesion energies per atom $(\mathrm{eV})$ & \\
$\mathrm{SiO}_{2}(D 2 h)$ & -3.56 & -3.91 & -4.16 & -4.03 \\
\hline \hline
\end{tabular}




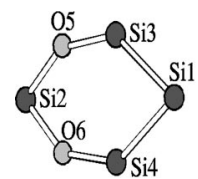

$\mathrm{Si}_{4} \mathrm{O}_{2}$

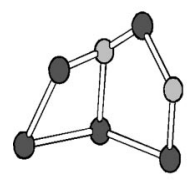

$\mathrm{Si}_{5} \mathrm{O}_{2}$

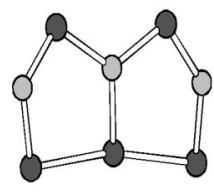

$\mathrm{Si}_{5} \mathrm{O}_{3}$

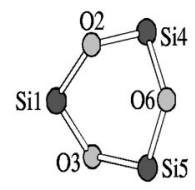

$\mathrm{Si}_{3} \mathrm{O}_{3}$

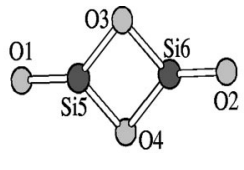

$\mathrm{Si}_{2} \mathrm{O}_{4}$
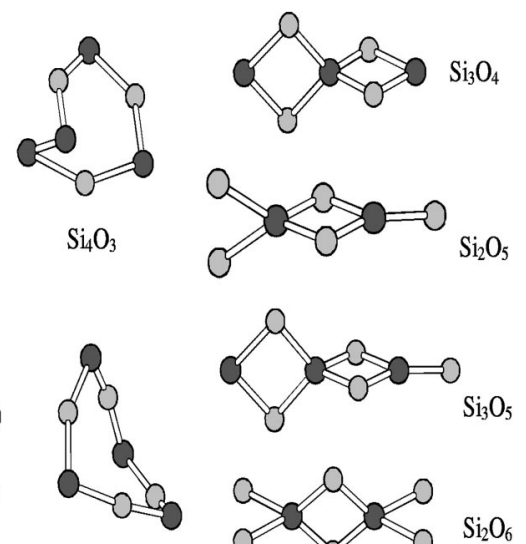

$\mathrm{Si}_{4} \mathrm{O}_{4}$
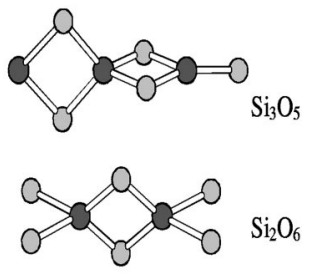

FIG. 1. Geometric structures of representative $\mathrm{Si}_{n} \mathrm{O}_{m}$ clusters for $n+m=6,7$, and 8 .

derestimate the cohesion energy in comparison with the more accurate values predicted by the $\mathrm{G} 2$.

In the search for possible structures of $\mathrm{Si}_{n} \mathrm{O}_{m} \quad(n, m$ $=1-8)$ clusters, initial structures were constructed based on the geometries of smaller clusters for which optimizations had been done. An inverse routine was used for constructing some alternative initial structures, in which the smaller structure was deduced from a larger cluster with a certain amount of atoms removed. The details of the calculation and the geometric results are reported elsewhere. ${ }^{18}$ The optimized structures deduced for some representative clusters are shown in Fig. 1. The structures of silicon-rich clusters mainly consist of planar or buckled rings that favor the constituent $\mathrm{Si}$ and $\mathrm{O}$ atoms to be alternately arranged. However, $\mathrm{Si}$ atoms bonded to up to four $\mathrm{O}$ atoms were found in oxygen-rich clusters. Large silicon-rich oxide clusters may have more than two pendant $\mathrm{Si}$ atoms. The structures obtained in this work are consistent with those found in previous studies. ${ }^{11,12,14,15,19}$ The cohesion energies per atom of the deduced configurations of $\mathrm{Si}_{n} \mathrm{O}_{m}$ clusters as functions of the $\mathrm{O}$ atom ratio based on total energy calculations with B3LYP are shown in Fig. 2. As shown in Fig. 2, the calculated cohesion energies with the economic basis set show minima at about 0.6 of the $\mathrm{O}$ atom ratio. The DFT calculations using the standard basis set of $6-31 \mathrm{G}^{*}$ for smaller clusters also show the same trend. The minimum of a larger-size cluster tends to shift to higher atom ratio of $\mathrm{O}$. It is expected that the minima would be stabilized at an atom ratio of $\mathrm{O}$ of about 0.67 (silicon dioxide) if the cluster size were sufficiently large. The results indicate that the energetically most favorable small clusters are silicon monoxide like. It is noted that the experimentally deposited silicon oxide material has an atom ratio of $\mathrm{O}$ of about 0.49 when the highest yield of $\mathrm{Si}$ nanowires is achieved. ${ }^{7}$

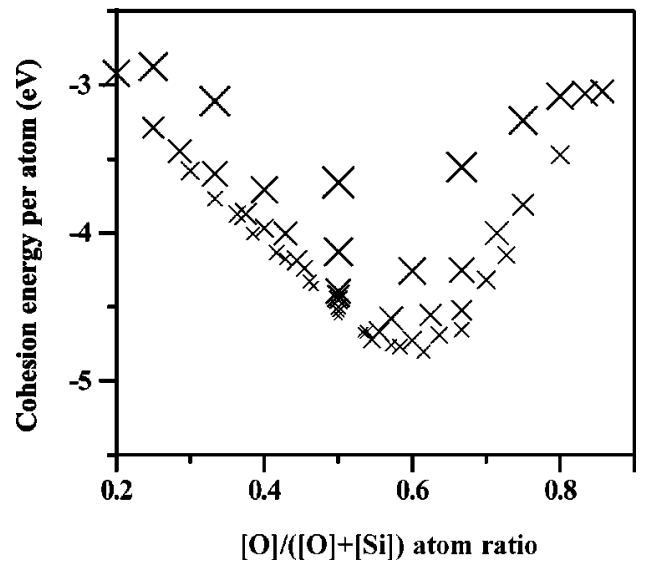

FIG. 2. Cohesion energy per atom of $\operatorname{Si}_{n} \mathrm{O}_{m}(n, m=1-8)$ clusters as a function of $\mathrm{O}$ ratio based on total energy calculations with B3LYP/3-21G:Si; 6-31G*:O. The decreasing size of the symbol $\times$ is related to increasing cluster size $(n+m)$.

Density-of-states (DOS) calculations ${ }^{20}$ were further done for every energetically most favorable structure described above, based on the coefficient matrix of eigenfunctions obtained from the B3LYP (with the economic basis set) calculations. The total DOS (TDOS) is projected onto the constituent atoms to deduce the contribution of the individual atoms to the total electronic structures. The projection allows the elucidation of the properties of electronic states in the bands and in the gap as well as their relationship with the atoms involved. ${ }^{20}$ Such a treatment was used in this work to find the atoms in which the frontier orbitals [the highest occupied molecular orbital (HOMO) and the lowest unoccupied MO (LUMO)] reside. Early studies ${ }^{21}$ have established that the overlap between the HOMO of one molecule and the LUMO of another would determine the nature of the chemical reaction. A smaller energy difference between the HOMO of one molecule (electron donor) and the LUMO of the other (electron acceptor) would indicate a more favorable reaction to take place. Following that, DOS analysis can show the reactive sites [where the partial DOS (PDOS) of the frontier orbitals shows larger intensities] and reactivity (by the closeness of the HOMO to the LUMO in the reaction systems) in the silicon oxide clusters.

We denote the closest MO's to the gap, which contain a significant contribution from the $\mathrm{Si}$ and $\mathrm{O}$ atoms, as $\mathrm{HOMO}_{\mathrm{Si}}, \mathrm{HOMO}_{\mathrm{O}}, \mathrm{LUMO}_{\mathrm{Si}}$, and $\mathrm{LUMO}_{\mathrm{O}}$, respectively. The calculation of TDOS and PDOS shows that there is no significant mixing between the atomic orbitals of $\mathrm{Si}$ and $\mathrm{O}$ atoms in the first few HOMO's and in the LUMO for most silicon-rich or oxygen-rich clusters because their frontier orbitals are mainly contributed from the unsaturated atoms. The atoms more saturated in the cluster would contribute to the $\mathrm{MO}$ at a higher binding energy.

Figure 3 shows the $\mathrm{LUMO}_{\mathrm{Si}}, \mathrm{LUMO}_{\mathrm{O}}, \mathrm{HOMO}_{\mathrm{Si}}$, and $\mathrm{HOMO}_{\mathrm{O}}$ of silicon oxide clusters as functions of the $\mathrm{O}$ atom ratio obtained from B3LYP calculations. Their fittings using fourth-order polynomials are shown as solid curves for the frontier orbitals of $\mathrm{Si}$ and as dashed curves for the frontier orbitals of O. Significant differences in the distribution of frontier orbitals are revealed for the systems with $\mathrm{O}$ ratio 


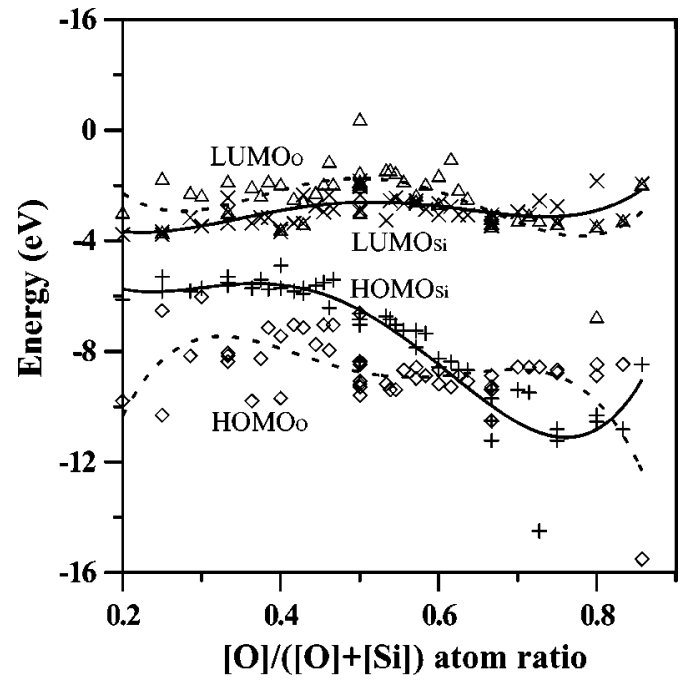

FIG. 3. $\mathrm{LUMO}_{\mathrm{Si}}(\times), \mathrm{LUMO}_{\mathrm{O}}(\triangle), \mathrm{HOMO}_{\mathrm{Si}}(+)$, and $\mathrm{HOMO}_{\mathrm{O}}$ $(\diamond)$ of $\mathrm{Si}_{n} \mathrm{O}_{m}$ clusters determined based on the calculations using B3LYP/3-21G:Si; 6-31G*:O. Their fittings using fourth-order polynomials are shown with solid curves for $\mathrm{LUMO}_{\mathrm{Si}}$ (upper) and $\mathrm{HOMO}_{\mathrm{Si}}$ (lower), while dashed curves represent $\mathrm{LUMO}_{\mathrm{O}}$ (upper) and $\mathrm{HOMO}_{\mathrm{O}}$ (lower).

greater than 0.62 (close to the 0.67 of silicon dioxide) and that smaller than 0.62 . With a smaller $\mathrm{O}$ ratio, $\mathrm{LUMO}_{\mathrm{O}}$ is higher than $\mathrm{LUMO}_{\mathrm{Si}}$, while $\mathrm{HOMO}_{\mathrm{O}}$ is lower than $\mathrm{HOMO}_{\mathrm{Si}}$. But the difference between them decreases as the $\mathrm{O}$ atom ratio increases. When the silicon-oxygen ratio approaches 1:2 or even large, $\mathrm{HOMO}_{\mathrm{Si}}$ becomes lower than $\mathrm{HOMO}_{\mathrm{O}}$. In addition, the $\mathrm{LUMO}_{\mathrm{Si}}$ and $\mathrm{LUMO}_{\mathrm{O}}$ are comparable and mixed together in general at and after such a point. The HOMO and LUMO variations coincide with a previous finding that the HOMO-LUMO gap decreases as the $\mathrm{O}$ content of a $\mathrm{Si}_{n} \mathrm{O}_{m}$ cluster is lowered. ${ }^{14}$

The interesting findings obtained above show that (1) the HOMO mainly locates at the $\mathrm{Si}$ atoms for silicon suboxide clusters $(m<2 n)$, but at the $\mathrm{O}$ atoms for oxygen-rich silicon oxide clusters; (2) the LUMO for most clusters locates at the $\mathrm{Si}$ atoms, particularly for the silicon suboxide clusters; and (3) the energy difference between $\mathrm{HOMO}_{\mathrm{Si}}$ and $\mathrm{LUMO}_{\mathrm{Si}}$ decreases significantly once the atom ratio of $\mathrm{O}$ is less than 0.62 . From the viewpoint of orbital interaction, the results indicate that, when $m<2 n$, the Si atom has a higher reactivity than the $\mathrm{O}$ atom and the extent of this reactivity depends on the atom ratio of the $\mathrm{O}$ atom. The smaller the $\mathrm{O}$ atom ratio, the higher is the reactivity. Once the number of $\mathrm{O}$ atoms approaches $2 n$ or larger, the reactivity becomes very poor. Therefore, the reaction between silicon suboxide cluster with any type of silicon oxide cluster would result in a bond formation between $\mathrm{Si}$ and $\mathrm{Si}$ of both clusters, whereas the reaction between oxygen-rich silicon oxide clusters would most likely lead to bonding between $\mathrm{O}$ and $\mathrm{Si}$ atoms in both clusters with a low reactivity. The trends of bond formations can be clearly seen from Fig. 4, which depicts the inverse of the energy difference and thus the reactivity for the formation of a Si-Si bond, a Si-O bond, or an O-O bond between two silicon oxide clusters as a function of the $\mathrm{Si}: \mathrm{O}$ ratio, calculated using the $\mathrm{LUMO}_{\mathrm{Si}}, \mathrm{LUMO}_{\mathrm{O}}, \mathrm{HOMO}_{\mathrm{Si}}$, and

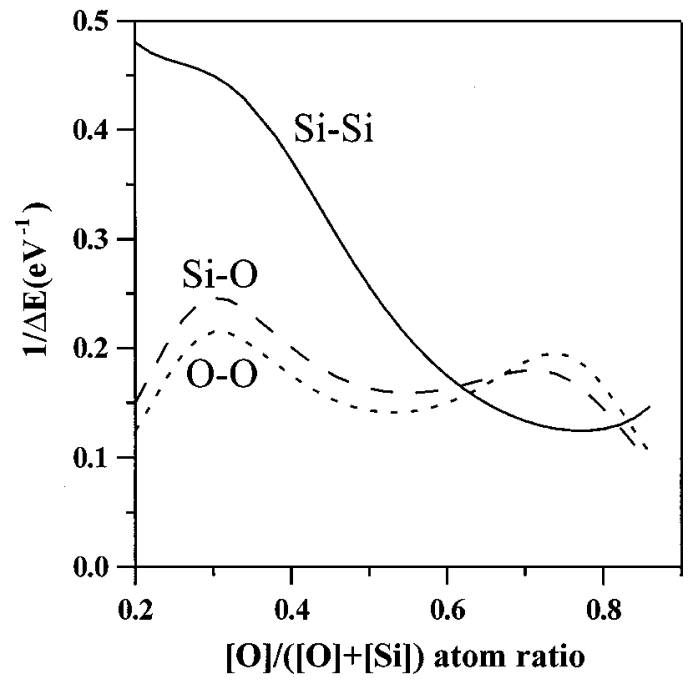

FIG. 4. The inverse of the energy difference $[\Delta E$ $=$ LUMO (electron acceptor) - HOMO (electron donor) $]$ and thus the reactivity (proportional to the inverse of the energy difference) for the formation of a Si-Si bond, a Si-O bond, or an O-O bond between two silicon oxide clusters as a function of the $\mathrm{Si}: \mathrm{O}$ ratio, calculated using the $\mathrm{LUMO}_{\mathrm{Si}}, \mathrm{LUMO}_{\mathrm{O}}, \mathrm{HOMO}_{\mathrm{Si}}$, and $\mathrm{HOMO}_{\mathrm{O}}$ fitted by fourth-order polynomials as described in Fig. 3.

$\mathrm{HOMO}_{\mathrm{O}}$ fitted by fourth-order polynomials as described in Fig. 3. Thus the reactivity to form a Si-Si bond of two silicon oxide clusters is significantly larger than that to form a $\mathrm{Si}-\mathrm{O}$ or $\mathrm{O}-\mathrm{O}$ bond, once the atom ratio of $\mathrm{O}$ is less than about 0.62 .

To lend support to the idea that the trend of reactivity can be reliably deduced from the analysis of frontier orbitals, we calculate the reaction energy barrier height and reaction heat between two $\mathrm{Si}_{4} \mathrm{O}_{2}, \mathrm{Si}_{3} \mathrm{O}_{3}$, and $\mathrm{Si}_{2} \mathrm{O}_{4}$ clusters, respectively. The reactions were assumed to occur at the following reactive sites (see Fig. 1): $\mathrm{Si} 1$ for $\mathrm{Si}_{4} \mathrm{O}_{2}$, Sil for $\mathrm{Si}_{3} \mathrm{O}_{3}$, and $\mathrm{O} 1$ for $\mathrm{Si}_{2} \mathrm{O}_{4}$, according to our DOS decompositions. The energy barrier and reaction heat at the B3LYP and 6-31G* level of calculation is $0.244 \mathrm{eV}$ and $-1.07 \mathrm{eV}$ for the reaction between two $\mathrm{Si}_{4} \mathrm{O}_{2}$ clusters and $2.63 \mathrm{eV}$ and $0.75 \mathrm{eV}$ for the reaction between two $\mathrm{Si}_{3} \mathrm{O}_{3}$ clusters. The smaller energy barrier and the exothermic reaction heat in the former reaction indicate a higher reactivity between two $\mathrm{Si}_{4} \mathrm{O}_{2}$ clusters than between two $\mathrm{Si}_{3} \mathrm{O}_{3}$ clusters. ${ }^{22}$ The significant difference in reaction energetics would ensure that the relative reactivity of $\mathrm{Si}_{4} \mathrm{O}_{2}$ clusters would remain higher than the $\mathrm{Si}_{3} \mathrm{O}_{3}$ clusters even at higher temperatures. On the other hand, there is no binding found between $\mathrm{Si}_{2} \mathrm{O}_{4}$ clusters, indicating an unfavorable bond formation. In addition, the reaction of two $\mathrm{Si}_{4} \mathrm{O}_{2}$ clusters occurring at $\mathrm{Si} 2$, the less reactive site, shows a much higher reaction barrier and endothermic heat $(2.22 \mathrm{eV}$ and

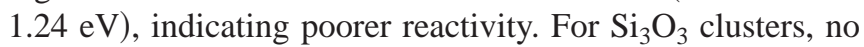
binding was found for the reaction occurring at the $\mathrm{O} 2$ site. All these results are consistent with the conclusion from the analysis of frontier orbitals.

The richer the Si atoms in the cluster, the higher will be the chance for them to form a Si-Si bond. However, the cohesion energy per atom of the silicon-rich clusters is much higher as shown in Fig. 2, indicating a smaller chance of 
their presence in the gas phase. The optimum ratio of $\mathrm{Si}$ atom to $\mathrm{O}$ atom in the silicon suboxide clusters to achieve the highest yield and formation of Si nanowire should be close to 1 , as also observed experimentally (about 49 at. \% of O). ${ }^{7}$ Our recent experiment using silicon monoxide has given the largest yield of Si nanowires. ${ }^{23}$ It is worthwhile noting that a recent experimental report on the formation of the crystalline phase of Si nanoclusters from the deposition of silicon-rich oxide $^{24}$ can also be understood in the context of our present study.

From the above observations, the following mechanism of oxide-assisted $\mathrm{Si}$ nanowire nucleation is supported. In this mechanism, part of the highly reactive $\mathrm{Si}$ atoms in the silicon suboxide clusters deposited on the substrate (possibly covered by silicon oxide) would form bonds with the substrate atoms, anchoring the cluster to the substrate so that the motion of the clusters is limited. The remaining reactive $\mathrm{Si}$ atoms facing outwards from the substrate are exposed to the vapor, favoring further stacking of silicon oxide clusters. They act as nuclei to absorb reactive silicon oxide clusters and facilitate the formation of $\mathrm{Si}$ nanowires with a certain crystalline orientation. The oxide-assisted growth of silicon nanowires is being accepted widely. ${ }^{25,26} \mathrm{We}$ expect that the present oxide-assisted formation mechanism of nanostructures may be applicable to a wide range of materials synthesis or design.

In conclusion, silicon suboxide clusters $\mathrm{Si}_{n} \mathrm{O}_{m}(m<2 n)$ possess high reactivity at the $\mathrm{Si}$ atoms, while small siliconmonoxide-like clusters are energetically more favorable in the gas phase. Therefore, the oxide-assisted nucleation of $\mathrm{Si}$ nanostructures is due to the formation of $\mathrm{Si}-\mathrm{Si}$ bonds when the highly reactive silicon oxide clusters meet.

The authors thank Professor K. M. Ho of Ames Laboratory for comments and suggestions. The work described in this paper was partially supported by a grant from City University of Hong Kong (Project No. 7000780) and by a grant from the Research Grant Council of the Hong Kong Special Administrative Region, China [Project No. 9040533, e.g., CityU 1033/00P].
*Electronic address: aprqz@ cityu.edu.hk

${ }^{1}$ C. R. Helms and B. E. Deal, The Physics and Chemistry of $\mathrm{SiO}_{2}$ and the $\mathrm{Si}-\mathrm{SiO}_{2}$ Interface (Plenum, New York, 1988).

${ }^{2}$ E. Desurvire, Phys. Today 47(X), 20 (1994).

${ }^{3}$ D. A. Muller, T. Sorsch, S. Moccio, F. H. Baumann, K. EvansLutterodt, and G. Timp, Nature (London) 399, 758 (1999).

${ }^{4}$ Y. F. Zhang, Y. H. Tang, N. Wang, D. P. Yu, C. S. Lee, I. Bello, and S. T. Lee, Appl. Phys. Lett. 72, 1835 (1998).

${ }^{5}$ T. Ono, H. Saitoh, and M. Esashi, Appl. Phys. Lett. 70, 1852 (1997).

${ }^{6}$ A. M. Morales and C. M. Lieber, Science 279, 208 (1998).

${ }^{7}$ N. Wang, Y. H. Tang, Y. F. Zhang, C. S. Lee, and S. T. Lee, Phys. Rev. B 58, R16 024 (1998).

${ }^{8}$ R. S. Wagner and W. C. Ellis, Appl. Phys. Lett. 4, 89 (1964).

${ }^{9}$ F. C. Frank, Discuss. Faraday Soc. 5, 48 (1949).

${ }^{10}$ J. A. W. Harkless, D. K. Stillinger, and F. H. Stillinger, J. Phys. Chem. 100, 1098 (1996).

${ }^{11}$ L. S. Wang, S. R. Desai, H. Wu, and J. B. Nichloas, Z. Phys. D: At., Mol. Clusters 40, 36 (1997).

${ }^{12}$ L. S. Wang, J. B. Nicholas, M. Dupuis, H. Wu, and S. D. Colson, Phys. Rev. Lett. 78, 4450 (1997).

${ }^{13}$ T. Sommerfeld, M. K. Scheller, and L. S. Cederbaum, J. Chem. Phys. 103, 1057 (1995).

${ }^{14}$ S. K. Nayak, B. K. Rao, S. N. Khanna, and P. Jena, J. Chem. Phys. 109, 1245 (1998).
${ }^{15}$ J. R. Chelikowsky, Phys. Rev. B 57, 3333 (1998).

${ }^{16}$ A. D. Becke, J. Chem. Phys. 98, 5648 (1993).

${ }^{17}$ R. Q. Zhang, T. S. Chu, and S. T. Lee, J. Chem. Phys. 114, 5531 (2001).

${ }^{18}$ T. S. Chu, R. Q. Zhang, and H. F. Cheung, J. Phys. Chem. B 105, 1705 (2001).

${ }^{19}$ L. S. Wang, H. Wu, S. R. Desai, J. Fan, and S. D. Colson, J. Phys. Chem. 100, 8697 (1996).

${ }^{20}$ R. Q. Zhang, C. S. Lee, and S. T. Lee, J. Chem. Phys. 112, 8614 (2000).

${ }^{21}$ R. Hoffmann, Rev. Mod. Phys. 60, 601 (1988), and references therein.

${ }^{22}$ T. Naito, S. Nagase, and H. Yamataka, J. Am. Chem. Soc. 116, 10080 (1994).

${ }^{23}$ Y. F. Zhang, Y. H. Tang, C. Lam, N. Wang, C. S. Lee, I. Bello, and S. T. Lee, J. Cryst. Growth 212, 115 (2000).

${ }^{24}$ K. Kim, M. S. Suh, T. S. Kim, C. J. Youn, E. K. Suh, Y. J. Shin, K. B. Lee, H. J. Lee, M. H. An, H. J. Lee, and H. Ryu, Appl. Phys. Lett. 69, 3908 (1996).

${ }^{25}$ J. L. Gole, J. D. Stout, W. L. Rauch, and Z. L. Wang, Appl. Phys. Lett. 76, 2346 (2000).

${ }^{26}$ Y. Q. Zhu, W. K. Hsu, N. Grobert, M. Terrones, H. Terrones, H. W. Kroto, D. R. M. Walton, and B. Q. Wei, Chem. Phys. Lett. 322, 312 (2000). 